\title{
Epidemiological Study of Bovine Fasciolosis: Prevalence and Risk Factor Assessment at Shahjadpur Upazila of Bangladesh
}

\author{
Md. Rezaul Karim*, Mohammad Showkat Mahmud, Md. Giasuddin \\ Animal Health Research Division, Bangladesh Livestock Research Institute, Bangladesh
}

Copyright (C) 2015 by authors, all rights reserved. Authors agree that this article remains permanently open access under the terms of the Creative Commons Attribution License 4.0 International License

\begin{abstract}
Fasciolosis is an economically important parasitic disease of cattle in Bangladesh. The aim of the study was to determine the prevalence of fasciolosis in cattle and identifying the potential risk factors associated with the disease. A cross-sectional survey was carried out from November 2012 to October 2013 on bovine fasciolosis in and around Shahjadpur upazila of Bangladesh. For this, a total of 762 fecal samples were collected from crossed breed cattle and all samples were subjected to standard sedimentation test at Animal Health Laboratory of BLRI regional station, Shahjadpur, Bangladesh. The overall prevalence of bovine fasciolosis was found to be $66.14 \%$ from 504 positive samples. From the various risk factor analysed, age categories of cattle, sex and seasonal influence were found to be significantly associated $(\mathrm{p}<0.01)$ with the prevalence of bovine fasciolosis. When considered the relationship with sex, it was observed that female $(70.3 \%)$ cattle had significantly $(\mathrm{p}<0.01)$ higher than male $(55.23 \%)$. As regards to age, bovine fasciolosis was significantly $(\mathrm{p}<0.01)$ higher in old cattle $(76.43 \%)$ compared to adult $(68.69 \%)$ and young $(48.62 \%)$. The seasonal influence of outbreak of this disease was significantly $(\mathrm{p}<0.01)$ higher in summer season $(72.44 \%)$ followed by winter $(67.75 \%)$ and rainy season $(58.55 \%)$. It can be concluded that these risk factors need to be taken in consideration when designing effective fasciolosis control management system for cattle in Bangladesh.
\end{abstract}

Keywords Prevalence, Risk Factor, Bovine Fasciolosis

\section{Introduction}

Fasciolosis is an economically important parasitic disease, which caused by trematodes of the genus Fasciola that migrate in the hepatic parenchyma, and establish and develop in the bile ducts [1]. Fasciola is commonly recognized as liver flukes and they are responsible for wide spread of morbidity and mortality in cattle characterized by weight loss, anemia and hypoproteinemia, reduced production of meat, milk, and wool, and expenditures for anthelmintics. The total global economic loss attributed to fasciolosis has been estimated earlier to be more than US $\$ 3$ billion per year [2].

It has involved a considerable agricultural and economic losses resulting from infection estimated at US\$2,000-3,000 million annually [3]. The disease has undergone a sharp rise and has emerged as a major zoonotic disease in many countries [4], with an estimation of 17 million infected people and up to 180 million at risk [5]. The human form of the disease has also become a major public health problem in several parts of the world [6]. In cattle, sheep and goat, the disease also causes high economic losses from anemia, reduced production, poor performance, condemnation of liver and an increased mortality $[7,8]$. The economic losses consist of costs of anthelmintics, drenches, labor, liver condemnation at meat inspection; and losses in production due to mortality, reduction in meat, milk and wool production; and reduction in growth rate, fertility and draught power [9].

The two most important species, Fasciola hepatica found in temperate area and in cooler areas of high altitude in the tropics and subtropics and Fasciola gigantica, which predominates in tropical area like as Bangladesh. The snail of the genus Lymnae natalensis and Lymnae truncatula are known as intermediate host in life cycle of fasciolosis. Infection with Lymnea truncatula is usually associated with herds and flocks grazing wet marshy land [10].

Generally in tropical countries when both species coexist F. gigantica is usually endemic in lower regions while F. hepatica is endemic in the high lands [11]. Fasciola gigantica is a fresh water snail and infection with this species is associated with livestock drinking from snails infected watering places as well as with grazing wetland. The major endemic areas for $F$. gigantica are large tropical regions of 
Africa and many areas of Asia including India, Pakistan and Bangladesh [12]. Shahjadpur region is a low land area. Farmers in this area reared high yielding animal for the fattening and milk production. Huge amount of snails are found in grazing area and river. Most of the farmers of this area use river's water for the drinking purpose of their cattle. That's why; areas like Shahjadpur are in high risk of liver fluke endemicity due to its low lying land, soil texture, vegetation groups, climatic condition. And also in relation to host and management, traditional husbandry system, malnourished condition and immunosuppression of host, improper sanitation, ignorance of animal health problems contribute greatly for parasite and its vector growth, development and transmission in this environment. Considering the economic importance and pathological effects of liver fluke infection and it's endemicity of cattle in Shahjadpur upazila, this study was conducted to determine the prevalence and risk factor of bovine fascioliasis in relation to age, sex, and seasons of the year.

\section{Materials and Method}

\subsection{Study Area and Period}

The research was carried out in crossed breed cattle of in and around Shahjadpur upazila (Figure 1). The area under study lies in the northern part of Bangladesh located in between $24^{\circ} 04^{\prime}$ and $24^{\circ} 25^{\prime}$ north latitudes and in between $89^{\circ} 31^{\prime}$ and $89^{\circ} 31^{\prime}$ east longitudes [13]. The mean annual rainfall of the study area is $1200 \mathrm{~mm}$ and the rain is monomodal with rainy season occurring from July to October. The annual average minimum and maximum temperature is $10^{\circ} \mathrm{C}$ and $30^{\circ} \mathrm{C}$, respectively.

All the tests were performed in Animal Health laboratory, BLRI Baghabari during the period from November 2012 to October 2013.

\subsection{Collection of Samples}

Fecal samples from 762 crossed breed cattle along with questionnaire based data on age, sex, health status were collected the farmers of Shahjadpur upazila and its surrounding areas from November-2012 to October-2013. Laboratory work was conducted in the Animal Health laboratory, BLRI, Baghabari, Shahjadpur, Sirajganj, Bangladesh. The study period was recorded on season wise from November-2012 to October-2013. From meteorological consideration, study period was divided into three seasons - such as winter (November-February), summer (March-June) and rainy (July-October). Animals were alienated into three groups: Young: $<3$ years, Adult: 3-5 years and Old: $>5$ years of age.

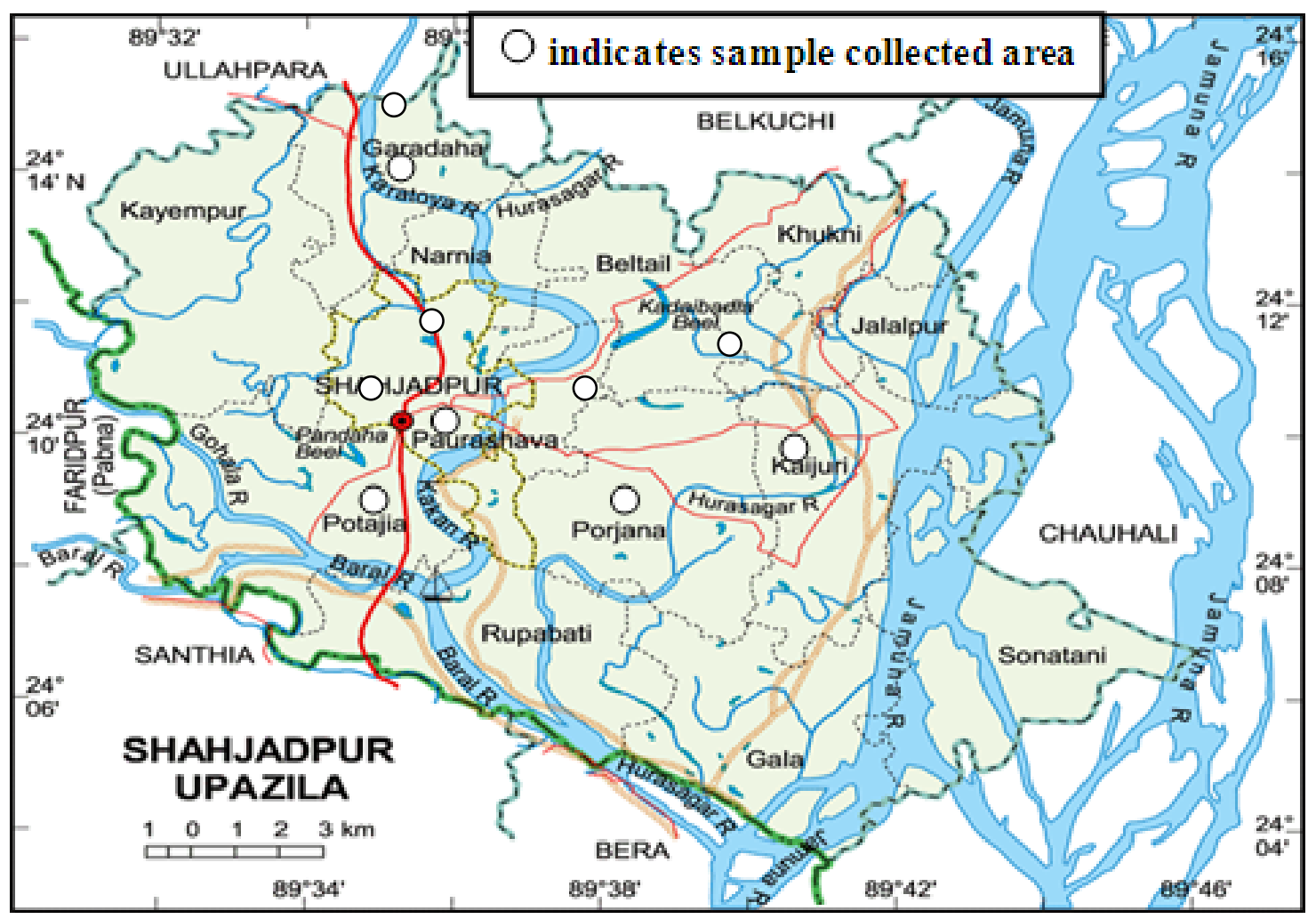

Figure 1. Sample collection area of Shahjadpur upazila. 


\subsection{Coprological Examination}

Each samples of 20-25 g of fecal material was collected directly from the rectum of each animal and freshly defected faeces in to plastic bottles with gloved hand. The samples were clearly labeled with universal bottles preserved with $10 \%$ formalin and each sample was clearly labeled with animal's identification (age, sex, and breed), date and place of collection. Samples were packed and dispatched in cool box to avoid development of eggs and hatching.

At Animal Health Laboratory of BLRI regional station of Shahjadpur, coprospic examination was performed to detect the presence of fasciola eggs using the standard sedimentation techniques $[14,15]$. The eggs of fasciola were identified by a drop of methylene blue solution was added to the sediment to differentiate between eggs of Paramphistomum species and Fasciola species where eggs of Fasciola species show yellowish colour while eggs of Paramphistomum species stain by methylene blue [16].

\subsection{Statistical Analysis}

Data were subjected to chi-square statistics using the Microsoft Excel 2007 Programme. Significant differences of the data were established by least significant difference at the $1 \%$ level of significance.

\section{Results and Discussion}

\subsection{Overall Prevalence and Intensity of Infection}

Among 762 faecal samples examined, 504 (66.14\%) were found infected with Fasciola spp. (Table 1) which is supported by the findings of Rahman and Mondol [17] and Gupta et al. [18] who recorded 53 and 70\% Fascioliasis in cattle in Bangladesh and India, respectively. The result is lower than the earlier report of Bahru and Ephraim [19] in Kaffa (86\%), Yadeta [20] in Western Showa (82.5\%), Dagne [21] in and around Debre Berhan (80\%).

On the other hand the result is higher than the earlier report of Biniam Tsegaye et al. [22], Afroze et al. [23] and much higher than the reports of Garrets [24] and Singh et al. [25] who recorded $41.41 \%, 25.2 \%, 22.4 \%$ and $19.3 \%$ prevalence of Fascioliasis in cattle, respectively. The variations in the findings with the earlier reports might be due to the difference in the sample size, selection of samples, breed of animals, period and place of study, climatic conditions of the experimental area, and technique of sample examination, managemental factors and the availability of the infected snail intermediate hosts.

\subsection{Age Related Prevalence of Fascioliasis in Cattle}

The age of the animals is considered as a major factor in the prevalence of Fascioliasis. Fascioliasis was observed significantly $(\mathrm{P}<0.01)$ higher in cattle aged above 5 years $(76.43 \%)$ and lower in the animals aged between 3-5 years $(68.69 \%)$ and the lowest in cattle of $<3$ years of age $(48.62 \%)$ as shown in Table 1 . The infection rate increased with the increase of age. This result is in agreement with the earlier findings of Molina et al. [9] and Bhutto et al. [26]. The highest level of infection in older group i.e., above 6 years $(62.62 \%)$ followed by in age groups of 4-6 years $(57.28 \%)$, $2-4$ years $(42.56 \%)$ and up to 2 year (17.87\%) [26]. The higher infection rate in older animals could be due to long time exposure to disease entity and their grazing habit close to submerge areas.

Table 1. Prevalence of bovine fasciolosis in both sexes of cattle

\begin{tabular}{|c|c|c|c|}
\hline Age (Year) & Sample no. & Isolates no. & Prevalence (\%) \\
\hline$<3$ & 218 & 106 & 48.62 \\
\hline 3 to 5 & 230 & 158 & 68.69 \\
\hline$>5$ & 314 & 240 & $76.43^{* *}$ \\
\hline Total & 762 & 504 & 66.14 \\
\hline \multicolumn{2}{|c|}{$0.000^{* *}$} \\
\hline
\end{tabular}

** Significant at $\mathrm{P}<0.01$

\subsection{Sex Related Prevalence of Fascioliasis in Cattle}

There was difference in the rate of infection in between the male and female cattle. In the females it was higher $(70.289 \%)$ than males $(55.238 \%)$ (Table 2$)$. The results of the present study are in agreement with the findings of Molina et al. [9] and Bhutto et al. [26] who observed higher prevalence in females as compared to male buffaloes. This finding is also in conformity with the previous reports of Chowdhury et al. [27]. The higher percentage of infection in the females can't be explained exactly but it might be assumed that hormonal influence as well as stress leading to immune-suppression may be associated with this phenomenon.

Table 2. Prevalence of bovine fasciolosis in both sexes of cattle

\begin{tabular}{|c|c|c|c|}
\hline Sex & Sample no. & Isolates no. & Prevalence (\%) \\
\hline Male & 210 & 116 & 55.25 \\
\hline Female & 552 & 388 & $70.29 * *$ \\
\hline Total & 762 & 504 & 66.14 \\
\hline $0.000^{* *}$ & $0.000^{* *}$ & \multicolumn{2}{|c|}{$0.000^{* *}$} \\
\hline
\end{tabular}

**Significant at $\mathrm{P}<0.01$

\subsection{Seasonal Influence for the Outbreak of Fascioliasis in Cattle}

Persistent infection of bovine Fascioliasis was prevailed throughout the year. The prevalence of bovine fasciolosis in each season of the study periods was also indicated in table 3 . The table shows the presence of significant difference 
$(p<0.01)$ in the prevalence of bovine fasciolosis between each season of the study periods. The highest $(72.44 \%)$ and the lowest $(58.55 \%)$ prevalence were observed in summer season and winter season, respectively. El-Bahy [28] reported that, the presence of infection throughout the year may be due to resistance of metacercariae for dissociation, especially with the presence of the shallow water, enough vegetation and humidity, continued exposure of the animals to encysted metacercariae from the banks of canal or ponds, especially during the dry season and no restriction on animal importation, grazing habits and movement between the infected and treated localities. This statement is also applicable for the present study.

Table 3. Seasonal influences for fasciolosis outbreak in cattle

\begin{tabular}{|c|c|c|c|c|}
\hline Time & Seasons & $\begin{array}{c}\text { Sample } \\
\text { no. }\end{array}$ & $\begin{array}{c}\text { Isolates } \\
\text { no. }\end{array}$ & $\begin{array}{c}\text { Prevalence } \\
(\%)\end{array}$ \\
\hline November-February & Winter & 263 & 154 & 58.55 \\
\hline March-June & Summer & 254 & 184 & $72.44 * *$ \\
\hline July-October & Rainy & 245 & 166 & 67.75 \\
\hline \multicolumn{2}{|c|}{ Total } & 762 & 504 & 66.14 \\
\hline \multicolumn{2}{|c|}{ Chi-square Test (P-value) } & \multicolumn{5}{|c}{$0.000^{* *}$} \\
\hline
\end{tabular}

** Significant at $\mathrm{P}<0.01$

\section{Conclusions}

Prevalence of bovine fasciolosis of Shahjadpur upazila is attributed by multifactorial risk factors which comprise host, parasite and environmental effects. The prevalence was significantly affected by sex, age and seasons of the year. Higher prevalence of bovine fasciolosis was recorded in females cattle than male and in older cattle ( $>5 \mathrm{yrs}$ ) than younger ( $>3 \mathrm{yrs}$ ) ones. In the natural foci of fasciolosis, the Fasciola and their intermediate and final hosts form an association posing a potential epidemiological threat and it is important that the existence and localization of such an association to be recognized beforehand so that the situation can be brought under control.

\section{REFERENCES}

[1] P. M. Troncy. Helminthes of livestock and poultry in Tropical Africa. In: Fischer. Manual of tropical veterinary parasitology. CAB international, UK. 63-73, 1989.

[2] FAO. Diseases of domestic animals caused by liver flukes: epidemiology, diagnosis and control of Fasciola, paramphistome, Dicroceoelium, Eurytrema and schistosome infections of ruminants in developing countries. FAO: Rome, 1994.

[3] J. C. Boray. Flukes of domestic animals. In Gaafar SM, Howard WE, Marsh RE. Parasites, Pests and Predators: B2 (World Animal Science). Eds. New York: Elsevier Science
Ltd; p. 179-218, 1985.

[4] S. Mas-Coma, M. D. Bargues, M. A. Valero. Fascioliasis and other plant-borne trematode zoonoses. Int J Parasitol, 35:1255-1278. 2005.

[5] World Health Organization. Report of the WHO Informal Meeting on Use of Triclabendazole in Fascioliasis Control. Geneva: The Organization. 2007.

[6] I. Fairweather. An advancement of learning. Triclabendazole Progress Report, 2005-2009, 83:139-150, 2009.

[7] J. A. Hammond, M. M. H. Sewell. The pathogenic effect experimental infection with Fasciola gigantica in cattle. $\mathrm{Br}$ Vet J, 130(5):453-465, 1974.

[8] J. P. Fabiyi, G. A. Adeleye. Bovine fasciolosis on the job plateau, Nigeria with particular referent to economic importance. Bull Anim Health Prod Afr, 30(1):41-43, 1982.

[9] E. C. Molina, E. A. Gonzaga and L. A. Lumbao. Prevalence of infection with Fasciola gigantica and its relationship to carcass and liver weights, and fluke and egg counts in slaughter cattle and buffaloes in Southern Mindanao, Philippines. Tropical Animal Health and Production, 37(3): 215-221,2005.

[10] W. J. A. Payne. An introduction to Animal Husbandry in the tropics fourth edition Black Well Science. Oxford. London, pp.47-74, 1990.

[11] J. C. Boray. Fascioliasis. In: Handbook Series in Zoonoses. Section C. Parasitic Zoonoses. Volume III (G.V Hillyer \& CE Hopla edit), CRC Press, Boca Raton-Florida: 71-88, 1982.

[12] S. Mas. Human fascioliasis. In: World Health Organization (WHO), Waterborne Zoonoses: Identification, Causes and Control, Publishing, London 22-305,2004.

[13] http://en.banglapedia.org/index.php?title=Shahjadpur_Upazi la (Last accessed on 21.06.2015).

[14] J. Hanson and Brian Perry. The epidemiology, diagnosis and control of helminthes parasites of ruminants. A handbook Rome: Food and Agricultural Organization of the United Nations pp.72, 1994.

[15] E. J. L. Soulsby. Heiminths, Arthropods and Protozoa of Domesticated Animals. Seventh edn. Bailliere Tindall and Cassell Ltd. London. 1982.

[16] Hansen J, Perry B (1994). The epidemiology, diagnosis and control of helminth parasites of ruminants. A hand book, International laboratory for research on Animal Disease. Nairobi, Kenya. pp. 31-36.

[17] M. H. Rahman and M. M. H. Mondal. Helminth parasites of cattle (Bos indices) in Bangladesh. Indian Journal of Parasitology, 7 (2): 173 - 174, 1983.

[18] S. C. Gupta and B. P. Singh. Fasciolosis in cattle and buffaloes in India. Journal of Veterinary Parasitology, 16(2): 139-145, 2002.

[19] Bahru G, Ephraim M (1979). Preliminary Survey of bovine Fasciolosis in Ethiopia. Ethiopian J. Agric. Sci. 1(1):5-12.

[20] Yadeta B (1994). Epidemiology of bovine and ovine fasciolosis anddistribution of its snail intermediate host in Western Showa, DVMThesis, Faculty of Veterinary 
Medicine, Addis AbabaUniversity, Debre Zeit, Ethiopia.

[21] Dagne M (1994). Survey on prevalence and economic significance of bovine fasciolosis in Debre Berhan region, DVM thesis, Faculty ofVeterinary Medicine, Addis Ababa University, Debre Zeit, Ethiopia.

[22] Biniam Tsegaye, Hanna Abebaw and Sisay Girma. Study on coprological prevalence of bovine fasciolosis in and around Woreta, Northwestern Ethiopia. Journal of Veterinary Medicine and Animal Health Vol. 4(7), pp. 89-92. 2012.

[23] S. Affroze, N Begum, M. S. Islam S. A. Rony M. A. Islam and M. M. H. Mondal. Risk Factors and Gross Pathology of Bovine Liver Fluke Infection at Netrokona District, Bangladesh. J. Anim. Sci. Adv., 3(2):83-89, 2013.

[24] G. Garrets. Gastro-intestinal Parasitic Infestation of cattle in some villages of Dhaka and Tangail Districts in Bangladesh.
Bangladesh Veterinary Journal. 9 (1- 4): 9-10, 1975.

[25] A. Singh, S. Srivastava, C. Shekhar and J. Singh. Prevalence of trematodes in bovines and snails. Indian Veterinary Journal, 86(2): 206-207, 2009.

[26] B. Bhutto, A. Arijo, M. S. Phullan, R. Rind. Prevalence of Fascioliasis in buffaloes under different agro-climatic areas of Sindh Province of Pakistan. Int J Agr. Biol., 14: 241-245, 2012.

[27] S. M. Z. H. Chowdhury, M. M. H. Mondal, F. M. S. Islam, M. J. F. A. Taimur, H. R. Biswas and M. Ershaduzzaman. Prevalence of fasciloiasis in cattle in Saver, Dhaka. Indian Veterinary Journal, 71 (2): 121 - 123, 1994.

[28] N. M. El-Bahy. Strategic Control of Fascioliasis in Egypt. Review article. Continual Scientific Committee of Pathology, Microbiology and Parasitology, Egypt, 1998. 